\title{
$P A X 3$ gene deletion detected by microarray analysis in a girl with hearing loss
}

Malgorzata Drozniewska ${ }^{1,2^{*}}$ and Olga Haus ${ }^{1,3}$

\begin{abstract}
Deletions of the PAX3 gene have been rarely reported in the literature. Mutations of this gene are a common cause of Waardenburg syndrome type 1 and 3 . We report a 16 year old female presenting hearing loss and normal intellectual development, without major features of Waardenburg syndrome type 1, and without family history of the syndrome. Her phenotype, however, overlaps with features of craniofacial-deafness-hand syndrome. Microarray analysis showed $\sim 862 \mathrm{~kb}$ de novo deletion at $2 \mathrm{q} 36.1$ including PAX3. The above findings suggest that the rearrangement found in our patient appeared de novo and with high probability is a cause of her phenotype.
\end{abstract}

Keywords: PAX3 gene, Array-CGH, Hearing loss, Waardenburg syndrome, Craniofacial-deafness-hand syndrome

\section{Background}

Hearing loss is a common feature which can be present as an isolated form or be one of an auditory phenotype symptoms [1]. Inherited hearing loss can be transmitted in an autosomal dominant, autosomal recessive, $\mathrm{X}$-linked or even in mitochondrial mode of inheritance. Although most of hearing loss cases are nonsyndromic, accompanying abnormalities can be present.

Hearing loss can be present in more than 400 genetic syndromes. Waardenburg syndrome (WS) is the most common type of hearing loss inherited as autosomal dominant trait. Phenotype associated with this syndrome includes, apart from hearing loss of various degree, pigmentary abnormalities of the skin, eye (heterochromia irides or bright blue irides) and hair (white forelock). Four types of WS have been distinguished, depending on the presence of other abnormalities. Patients with WS type 1 (WS1) present mutation within Paired Box 3 (PAX3) gene, however it has been shown to be present in only $45 \%$ of the WS1 syndrome. Heterozygous mutations of this gene have been reported in both sporadic and familial cases [1]. Up to date more than 100 PAX3 mutations have been recorded in the Human Gene Mutations Database, of which about $50 \%$ are missense/nonsense mutations. Partial or

\footnotetext{
* Correspondence: m.drozniewska@gmail.com

'Department of Clinical Genetics, Collegium Medicum Nicolaus Copernicus

University, Skłodowskiej-Curie 9, 85-094 Bydgoszcz, Poland

${ }^{2}$ West Midlands Genetics Laboratories, Birmingham Women's Hospital NHS

Foundation Trust, Edgbaston, B15 2TG Birmingham, UK

Full list of author information is available at the end of the article
}

whole gene deletions have been reported in $\sim 10 \%$ of patients $[2,3]$. Rare subtype, craniofacial-deafness-hand syndrome (CDHS), can also be caused by PAX3 mutations.

$P A X 3$ gene belongs to the transcription factors paired box family and has been mapped to chromosome $2 \mathrm{q} 35$. As shown by Bondurand et al., PAX3, together with SOX10, strongly activates microphtalmia-associated transcription factor (MITF) and contributes to pigmentation abnormalities [4].

We report on a female patient with congenital sensorineural hearing loss with minor facial dysmorphism partially overlapping with features characteristic for Waardenburg syndrome 1 and craniofacial-deafness-hand syndrome in which PAX3 de novo deletion has been identified by microarray analysis.

\section{Case presentation \\ Clinical report}

The 16 years old girl was referred for genetic counselling due to congenital hearing loss and subtle dysmorpic features. The proband is the second child of non-consanguineous parents. She has two healthy sisters. She was born at term after an uneventful pregnancy. Her birth weight was $3200 \mathrm{~g}$, length $53 \mathrm{~cm}$. Apgar score was 10. Synophrys and low set ears were noted at birth.

Her early psychomotor development was normal, without any notable delay. Later she presented speech impairment due to hearing problems, noted at the age of 2 . She attended a school for children with hearing impairment. 
At the age of 16 she was hospitalised at the Endocrinology Unit due to hirsutism and hypercholesterolemia. Physical examination revealed seborrheic dermatitis, astigmatism, and profound sensorineural hearing loss. Hirsutism was scored at 6 according to the FerrimanGallwey scale. Sex hormone levels were normal.

Phenotype examination at the genetic counselling centre revealed the presence of wide set eyes of brilliant blue irides, dystopia canthorum, shortened upslanting palpebral fissures, hypoplastic alae nasi, hirsutism (Figure 1). Please note that synophrys is not visible as she keeps her eyebrows plucked. She did not present white forelock characteristic for WS, however it cannot be excluded that she dyed her hair (despite denying it). Intellectual development was normal. Both parents were phenotypically normal and neither of them presented any features suggestive of WS.

\section{Methods of detection \\ Cytogenetics}

Chromosomal analysis was performed according to standard procedures on GTG-banded metaphase spreads, obtained from peripheral blood lymphocytes.

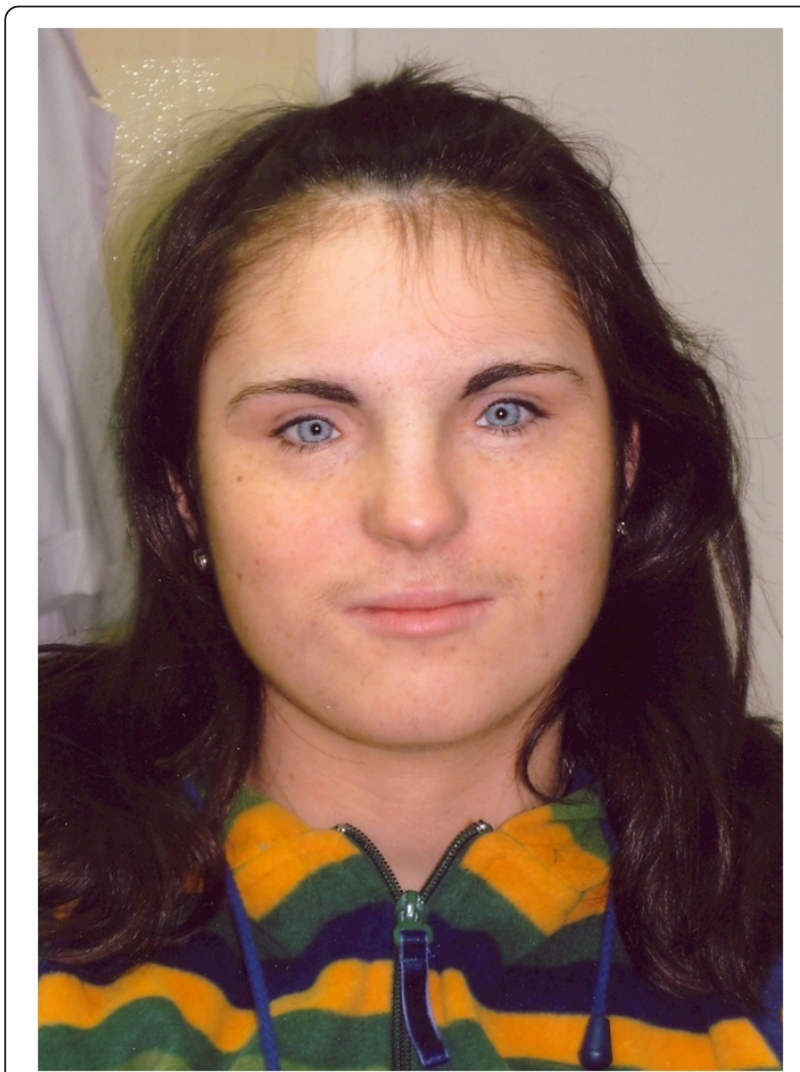

Figure 1 Facial appearance of the patient at the age of 16. Note brilliant blue irides, hypertelorism, dystopia canthorum, hirsutism.

\section{Array-CGH}

An oligo array-CGH was performed using the Human Genome CGH Microarray Kit and SurePrint G3 4x180K Human Kit (Agilent Technologies, Santa Clara, CA, USA), according to the manufacturer's protocols. The Agilent Feature Extraction software has been used to perform image analysis. Array data were compared with the human genome reference sequence hg19 (February 2009). Genomic DNA was extracted from peripheral blood lymphocytes.

\section{Method of confirmation (FISH)}

Fluorescence in situ hybridisation (FISH) was performed on metaphase spreads by using PAX3 Breakapart Probe (Cytocell, Cambridge, UK) according to manufacturer's protocol. Metaphases were analysed with Nikon Eclipse fluorescent microscope. Images were analysed and archived with Applied Spectral Imaging software (Applied Spectral Imaging, Edingen, Neckerhausen, Germany).

\section{Results}

Cytogenetic GTG analysis revealed normal female karyotype.

Array CGH experiment disclosed an interstitial deletion within long arm of chromosome 2. The deletion region was found to be $\sim 862 \mathrm{~kb}$ in size and ranged between oligos 222,562,885-223,424,791 (UCSC Genome Browser on Human, Feb. 2009 (GRCh37/hg19) Assembly). This region is localised within band $2 \mathrm{q} 36.1$ and contains $P A X 3$ gene, CCSC140 gene and a part of SGPP2. Overview of the deleted region, together with its aCGH profile is shown on Figure 2.

FISH examination using $P A X 3$ break apart probe confirmed the aCGH finding.

Combined parental follow-up by standard cytogenetics and microarray testing showed no evidence of deletion of 2q36.1 in either parent. FISH studies using the same probe excluded deletion or any balanced rearrangement involving 2q36.1 region. Figure 3 shows FISH results of the proband (3A) and proband's mother (3B).

Molecular investigation of GJB2 gene in the girl excluded the presence of its most common mutation, del35G.

The above findings suggest that the rearrangement found in our patient appeared de novo and with high probability is a cause of her phenotype.

\section{Discussion}

We report a patient with a de novo $2 \mathrm{q} 36.1$ deletion of $862 \mathrm{~kb}$, including $P A X 3$ gene, which is a member of the transcription factors family [4-6]. In humans, constitutional mutations of $P A X 3$ lead to Waardenburg syndrome (WS) or Craniofacial-deafness-hand (CFDS) syndrome $[1,7]$. Acquired mutations or rearrangements of $P A X 3$ may cause alveolar rhabdomyosarcoma [5]. PAX3 gene contains 10 exons and encodes protein of $98 \%$ homology to the mouse orthologue $[3,5]$. 


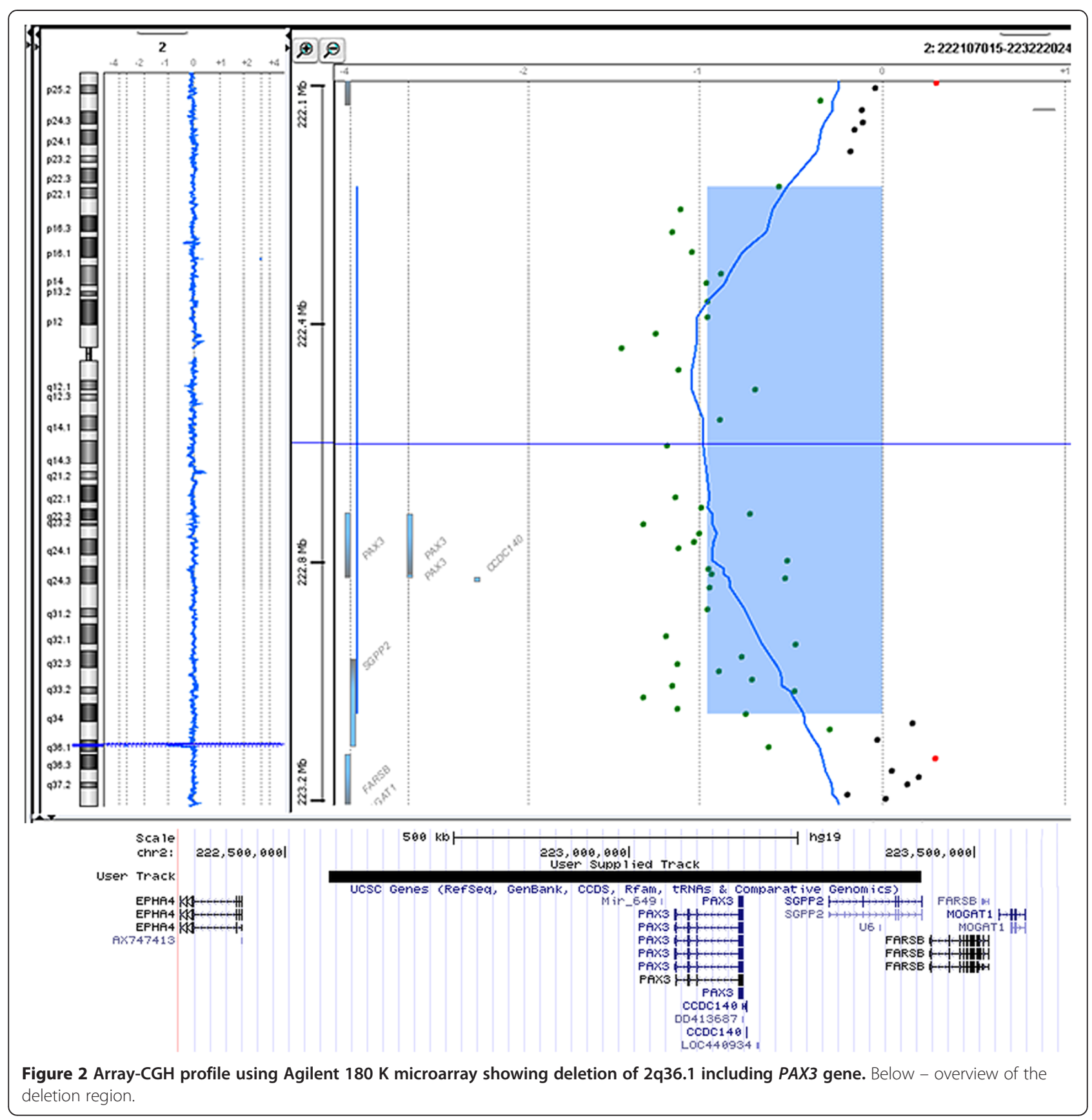

Craniofacial-deafness-hand syndrome (MIM \#122880) was first described by Sommer et al. in 1983 [7]. Several follow-up studies were performed since, and genotypephenotype correlation was established.

Point mutations of PAX3 account for $\sim 90 \%$ of WS1 and WS3 (Waardenburg Syndrome type 3) in patients meeting clinical diagnostic criteria, whereas partial and whole PAX3 deletions can be causal in only $~ 6 \%$ of cases [8]. Diagnostic tests are based mainly on sequencing of genes involved in WS etiology, however MLPA technique can also be of use $[8,9]$.
There are larger deletions of chromosome 2q recorded in the Decipher database, which also include PAX3 gene. Of these cases one shows similar phenotype to our patient, including synophrys, hypertelorism and iris pigmentation disturbances (ID: 248718). Deletion reported in this patient is $4.95 \mathrm{Mb}$ in size, and its size likely contributes to other clinical features, such as intellectual disability. Comparison of cases recorded in Decipher database and this case is shown on Figure 4.

Previous reports suggested that PAX3 deletions did not necessarily result in distinct WS phenotype, which 


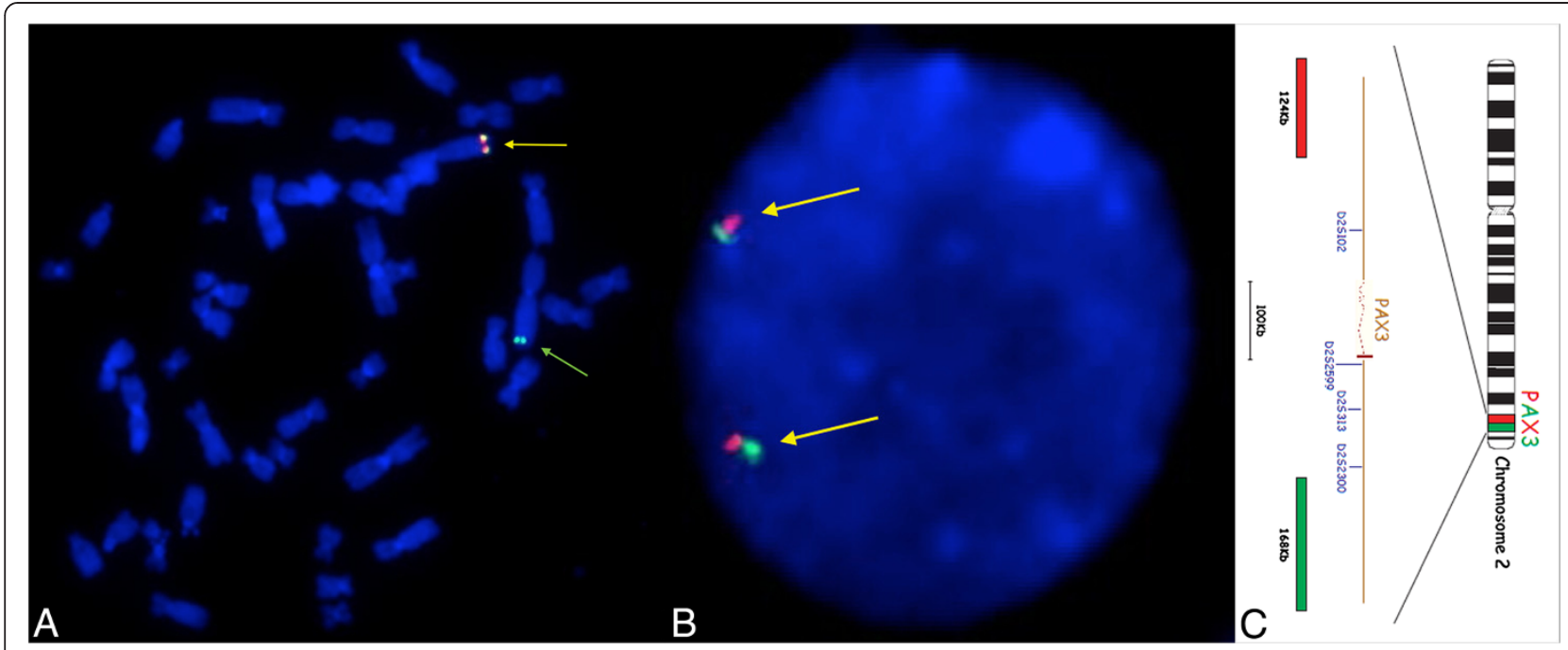

Figure 3 FISH results with PAX3 breakapart probe (Auqarius, Cytocell). A - patient's metaphase spread. Arrows indicate fluorescent signals. Yellow arrow shows normal chromosome 2 with both fluorescent signals present. Note absence of one red signal on one of the chromosomes 2 , indicated by green arrow. B - patient's mother blood cell nucleus. Yellow arrows indicate fluorescent signals showing no deletion within examined loci. The same signal pattern was observed in patient's father. $\mathbf{C}$ - schematic overview of PAX3 probe (Vysis). Red bar represents proximal region of probe coverage (observed as red signal), green bar - distal region (observed as green signal).

can raise the question of $P A X 3$ penetrance and associated variable phenotype. In addition authors suggested that size of rearrangement can also affect manifestation of WS clinical features [8], however no relationship was found between severity of clinical features and the type of mutation [3].
It is not possible to make a strict correlation between our patient's phenotype and either WS or CFDS. The diagnosis of Waardenburg syndrome can be made when at least two major or one major and two minor phenotypic criteria are met. Presence of dystopia canthorum and hearing loss (major criteria) together with synophrys,

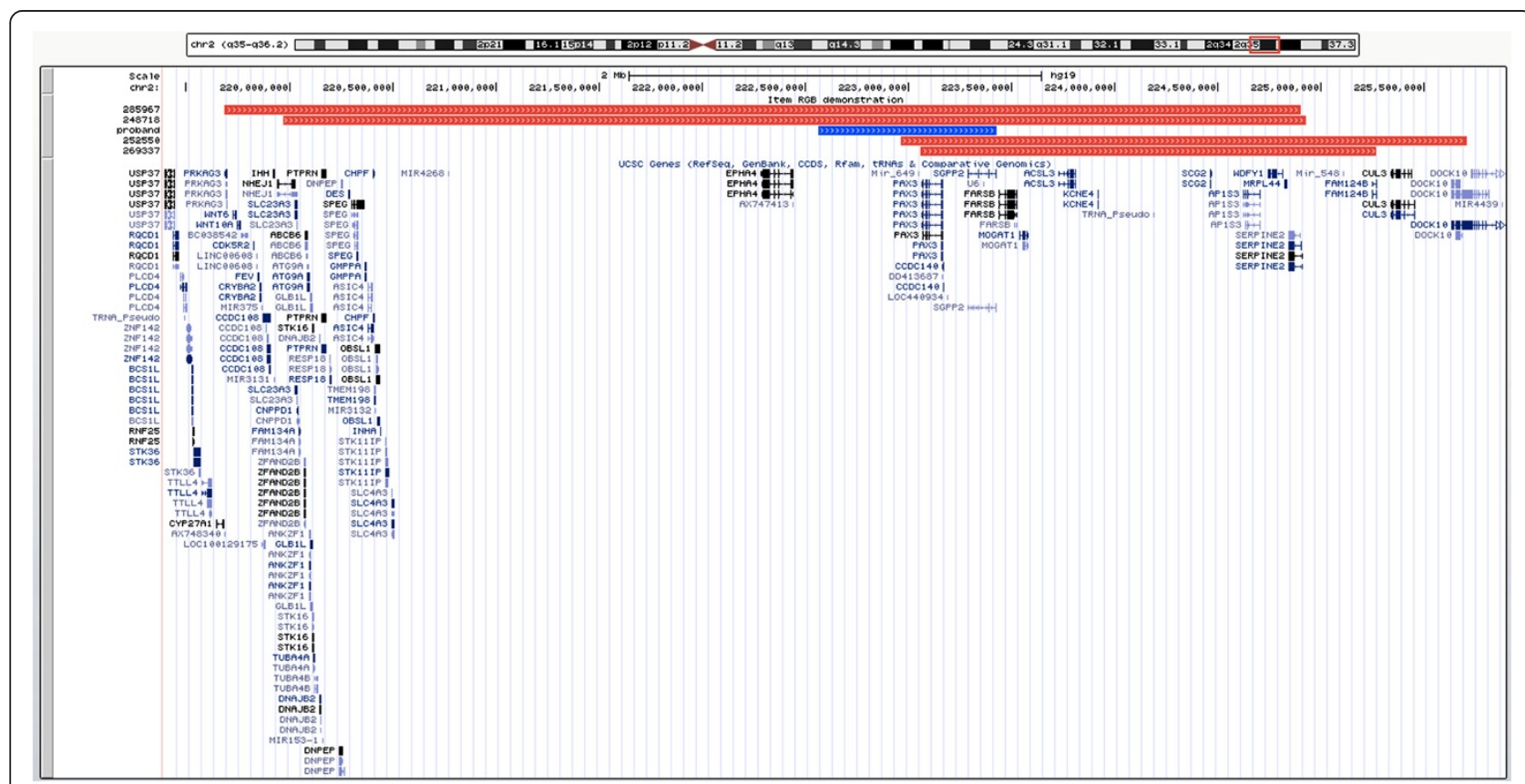

Figure 4 Schematic comparison of $2 q$ deletions including PAX3 recorded in the Decipher database and presented case. Region of deletion seen in our patient is represented by blue bar. Red bars represent Decipher cases. ID numbers are shown on sidebar. 


\begin{tabular}{|c|c|c|c|}
\hline Phenotype & $\begin{array}{l}\text { Present } \\
\text { case }\end{array}$ & $\begin{array}{c}\text { Sommer and } \\
\text { Bartholomew [7] }\end{array}$ & Gad et al. [1] \\
\hline Flat facial profile & - & + & + \\
\hline Hypertelorism & + & + & + \\
\hline $\begin{array}{l}\text { Downslanting palpebral } \\
\text { fissures }\end{array}$ & + & + & + \\
\hline Heterochromia of irides & - & - & - \\
\hline Synophrys & + & - & - \\
\hline Depressed nasal bridge & - & + & + \\
\hline Contractures of digits & - & + & + \\
\hline Hirsutism & + & - & - \\
\hline Normal intelligence & + & + & + \\
\hline Hearing loss & + & + & + \\
\hline Pigmentation abnormalities & - & - & - \\
\hline Dystopia canthorum & + & - & - \\
\hline Brilliant blue irides & + & - & - \\
\hline
\end{tabular}

Legend: (+) presence of feature, (-) absence of feature.

hypoplastic alae nasi and bright blue irides (minor criteria) could be convincing enough to make a diagnosis of WS1. However, comparison of the phenotypes of the two syndromes suggests that the patient could also be qualified as having craniofacial-deafness-hand syndrome. Despite different type of genomic changes described in our patient and patients reported in the literature, similar dysmorphic features and normal intellectual development can lead to conclusion that these patients can be classified into the same group. Comparison of clinical features present in described case and in patients reported by Sommer and Bartholomew [7] Gad et al. [1] is shown in Table 1.

Further molecular analysis of the second allele is to be considered in terms of any mutations present.

\section{Conclusion}

In conclusion, our case can be another example of $P A X 3$ rearrangement causing distinct but variable phenotype. It also shows that it may be recommended to perform array-CGH analysis in addition to $P A X 3$ mutations analysis in the patients with hearing loss and dysmorphy.

\section{Consent}

Approval to conduct the study was granted by the local Bioethics Committee. Written informed consent was obtained from parents of the patient for publication of this Case report and any accompanying images. A copy of the written consent is available for the review by the Editor-in-Chief of this journal.
Competing interests

The authors declare that they have no competing interests.

\section{Authors' contributions}

MD carried out microarray and FISH testing, and drafted the manuscript. $\mathrm{OH}$ counseled the patient and critically reviewed the manuscript. All authors read and approved the final manuscript.

\section{Acknowledgements}

This work was supported by grant of Ministry of Science and Higher Education NN401 010336

\section{Author details}

'Department of Clinical Genetics, Collegium Medicum Nicolaus Copernicus University, Skłodowskiej-Curie 9, 85-094 Bydgoszcz, Poland. ${ }^{2}$ West Midlands Genetics Laboratories, Birmingham Women's Hospital NHS Foundation Trust, Edgbaston, B15 2TG Birmingham, UK. ³epartment of Hematology, Blood Cancer and Bone Marrow Transplantation, Medical University, Pasteura 4, 50-367 Wroclaw, Poland.

Received: 3 February 2014 Accepted: 10 April 2014

Published: 29 April 2014

\section{References}

1. Gad A, Laurino M, Maravilla KR, Matsushita M, Raskind WH: Sensorineural deafness, distinctive facial features, and abnormal cranial bones: a new variant of waardenburg syndrome? Am J Med Genet 2008, 146A:1880-1885.

2. The Human Mutation Database. http://www.hgmd.cf.ac.uk/ac/gene.php? gene $=P A X 3$.

3. Hazan F, Ozturk AT, Adibelli H, Unal N, Tukun A: A novel missense mutation of the paired box 3 gene in a turkish family with waardenburg syndrome type 1. Mol Vis 2013, 19:196-202.

4. Bondurand N, Pingault V, Goerich DE, Lemort N, Sock E, Le Caignec C, Wegner M, Goossens M: Interaction among SOX10, PAX3 and MITF, three genes altered in waardenburg syndrome. Hum Mol Genet 2000, 9:1907-1917.

5. Barber TD, Barber MC, Cloutier TE, Friedman TB: PAX3 gene structure, alternative splicing and evolution. Gene 1999, 237:311-319.

6. Pasteris NG, Trask BJ, Sheldon S, Gorski JL: Discordant phenotype of two overlapping deletions involving the PAX3 gene in chromosome 2 q35. Hum Mol Genet 1993, 2:953-959.

7. Sommer A, Bartholomew DW: Craniofacial-deafness-hand syndrome revisited. Am J Med Genet 2003, 123A:91-94.

8. Milunsky JM, Maher TA, Ito M, Milunsky A: The value of MLPA in waardenburg syndrome. Genet Test 2007, 11:179-182.

9. Matsunaga T, Mutai H, Namba K, Morita N, Masuda S: Genetic analysis of PAX3 for diagnosis of waardenburg syndrome type I. Acta Otolaryngol 2013, 133:345-351.

doi:10.1186/1755-8166-7-30

Cite this article as: Drozniewska and Haus: PAX3 gene deletion detected by microarray analysis in a girl with hearing loss. Molecular Cytogenetics 2014 7:30.

\section{Submit your next manuscript to BioMed Central and take full advantage of:}

- Convenient online submission

- Thorough peer review

- No space constraints or color figure charges

- Immediate publication on acceptance

- Inclusion in PubMed, CAS, Scopus and Google Scholar

- Research which is freely available for redistribution 